E D I T O R I A L

JSRM Code: 016020100006

\title{
Organoids enabling COVID-19 research and significance of Biomaterial technologies
}

\begin{abstract}
Organoids, which are self-organizing 3D culture systems, have greatly expanded our understanding of molecular interactions between cells and their niche, mechanisms underlying development and organ regeneration apart from serving as highly valuable in vitro model systems for drug testing and platforms for personalized therapeutics ${ }^{[1]}$. Organoids grow in vitro into a complete mimic of an organ of interest containing all the cell types present in that organ in a three-dimensional (3D) biomaterial environment with the source of those cell types derived from the organ of interest itself or pluripotent stem cells ${ }^{[1]}$.
\end{abstract}

In virology, organoids are particularly useful as they permit studies on viruses that are difficult to cultivate ${ }^{[2]}$. During the 2015 Zika virus (ZIKV) epidemic, it was human cerebral organoids which provided proof of causation for strong association between ZIKV infections and microcephaly during brain development in embryo as the virus destroys the neural precursors while post-natal infections did not affect the brain ${ }^{[3]}$. Organoids also help to identify species susceptibility to viruses. Human airway organoids, which could be expanded in vitro over years and cryopreserved for future use, have been useful to assess pandemic threats to humans from animal influenza viruses ${ }^{[2-5]}$.

Amidst the ongoing COVID pandemic due to the novel coronavirus (SARS-CoV-2), though the virus can be cultivated on the VERO cell line, it is capillary and kidney organoids developed in vitro which have been able to offer researchers with more beneficial information on how the virus spreads through the organs and leads to kidney damage in severely ill patients ${ }^{[2]}$. Intestinal organoids have been able to reveal that high levels of ACE2 receptor expression through which the virus enters the lung tissue is also present in the gastrointestinal tract establishing GIT as another major entry route for the infection other than the respiratory route ${ }^{[6]}$. While the tissues from infected human COVID patients have been used to cultivate the virus, the virus has not yet been able to be cultivated from faecal samples or anal swabs of Chinese horseshoe bats which are thought to be the zoonotic source of the virus. Intestinal organoids have been reported from the horseshoe bat species which could be a potential solution to confirm the possible Zoonotic origin of this virus ${ }^{[7]}$. In the wake of no definite vaccine or drug to combat COVID-19 its complications or sequalae, organoid cultures made of airway club cells and alveolar type 2 (AT2) cells are precious resources for testing drug candidates against SARS-CoV-2 ${ }^{[8]}$.

In the current issue of JSRM, Ozaki et al ${ }^{[9]}$ have investigated the various aspects that govern the development of a successful "organoid assay" by employing co-culture of lung fibroblasts and AT2 epithelial cells in Matrigel. They further tested the utility of their organoid in the context of COVID-19 by examining the expression of the receptors on their organoids for the SARS-CoV-2 virus entry and have established that their organoid is highly relevant and suitable for pre-clinical experimentation to understand COVID-19 disease pathogenesis other than helping to decipher cellular responses to the virus, especially in terms of age-induced changes in the lung epithelium ${ }^{[9]}$.

Organoid development needs two essential components, cells and biomaterials. Though biomaterial scaffolds such as Matrigel are the most commonly employed ${ }^{[9,10]}$, they have limitations including a limited capacity to vary their mechanical properties and biochemical composition which will influence the differentiation and properties of the organoids being formed ${ }^{[10]}$. Synthetic hydrogels such as nanofibrous hydrogels, polyethylene glycol (PEG)-based hydrogels, multi-arm PEGs with vinyl sulphone functionality (PEG-VS) are viewed as potential solutions ${ }^{[11]}$. A thermo-reversible gelation polymer (TGP) based chemically defined system with no matrix proteins has been shown to be capable of nearly $10^{72}$-fold expansion of human pluripotent stem cells with strong maintenance of pluripotency ${ }^{[12]}$, along with maintenance of the native phenotype of different types of cells grown in it, earlier reported in JSRM ${ }^{[13]}$. Even adult cells such as the chondrocytes derived from osteoarthritic patients have been shown to organize into a tissue like structure in this $3 \mathrm{D}$ system with pluripotent and multipotent stem cells growing along with differentiated cells ${ }^{[14]}$ without inducing gene abnormalities ${ }^{[15]}$, apart from enabling replication of viruses such as the hepatitis $\mathrm{C}$ virus $(\mathrm{HCV})^{[16]}$ Though naturally derived biomaterials such as alginate ${ }^{[17]}$ and chitosan $^{[18]}$ have also been explored for similar investigations, research into biomaterials which are purely synthetic, highly biocompatible, possessing ability to maintain the native phenotype of cells and allowing propagation of viruses without mutations is of significant importance with reference to organoid based approach in virology including that of SARS-CoV-2 and improvise regenerative medicine-based solutions.

\section{References}

1. Kim J, Koo BK, Knoblich JA. Human organoids: model systems for human biology and medicine. Nat Rev Mol Cell Biol. 2020;21(10):571-584.

2. Clevers H. COVID-19: organoids go viral. Nat Rev Mol Cell Biol. 2020;21(7):355-356.

3. Qian X, Nguyen HN, Song MM, Hadiono C, Ogden SC, Hammack C, Yao B, Hamersky GR, Jacob F, Zhong C, Yoon KJ, Jeang W, Lin L, Li Y, Thakor J, Berg DA, Zhang C, Kang E, Chickering M, Nauen D, Ho CY, Wen Z, Christian KM, Shi PY, Maher BJ, Wu H, Jin P, Tang H, Song H, Ming GL. BrainRegion-Specific Organoids Using Mini-bioreactors for Modeling ZIKV Exposure. Cell. 2016;165(5):1238-1254. 
4. Hui KPY, Ching RHH, Chan SKH, Nicholls JM, Sachs N, Clevers H, Peiris JSM, Chan MCW. Tropism, replication competence, and innate immune responses of influenza virus: an analysis of human airway organoids and ex-vivo bronchus cultures. Lancet Respir Med. 2018;6(11):846-854.

5. Zhou J, Li C, Sachs N, Chiu MC, Wong BH, Chu H, Poon VK, Wang D, Zhao X, Wen L, Song W, Yuan S, Wong KK, Chan JF, To KK, Chen H, Clevers H, Yuen KY. Differentiated human airway organoids to assess infectivity of emerging influenza virus. Proc Natl Acad Sci U S A. 2018;115(26):6822-6827.

6. Lamers MM, Beumer J, van der Vaart J, Knoops K, Puschhof J, Breugem TI, Ravelli RBG, Paul van Schayck J, Mykytyn AZ, Duimel HQ, van Donselaar E, Riesebosch S, Kuijpers HJH, Schipper D, van de Wetering WJ, de Graaf M, Koopmans M, Cuppen E, Peters PJ, Haagmans BL, Clevers H. SARS-CoV-2 productively infects human gut enterocytes. Science. 2020;369(6499):50-54.

7. Zhou J, Li C, Liu X, Chiu MC, Zhao X, Wang D, Wei Y, Lee A, Zhang AJ, Chu H, Cai JP, Yip CC, Chan IH, Wong KK, Tsang OT, Chan KH, Chan JF, To KK, Chen H, Yuen KY. Infection of bat and human intestinal organoids by SARS-CoV-2. Nat Med. 2020;26(7):1077-1083.

8. Wang J, Li X, Wang A, Zhao F, Wu Q, Li L, Yu H, Wu J, Chen H. Organoid technology demonstrates effects of potential drugs for COVID-19 on the lung regeneration. Cell Prolif. 2020:e12928

9. Ozaki M, Kagawa S, Ishii M, Hegab AE. Optimizing the in vitro colony-forming assay for more efficient delineation of the interaction between lung epithelial stem cells and their niche. $\mathrm{J}$ Stem Cells Regen Med 2020;16 (2): 50-62.

10. He J, Zhang X, Xia X, Han M, Li F, Li C, Li Y, Gao D. Organoid technology for tissue engineering. J Mol Cell Biol. 2020;12(8):569-579.

11. Oksdath M, Perrin SL, Bardy C, Hilder EF, DeForest CA, Arrua RD, Gomez GA. Review: Synthetic scaffolds to control the biochemical, mechanical, and geometrical environment of stem cell-derived brain organoids. APL Bioeng. 2018;2(4):041501.
12. Lei Y, Schaffer DV. A fully defined and scalable 3D culture system for human pluripotent stem cell expansion and differentiation. Proc Natl Acad Sci U S A. 2013;110(52): E503948.

13. Kataoka K, Huh N. Application of a thermo-reversible gelation polymer, mebiol gel, for stem cell culture and regenerative medicine. J Stem Cells Regen Med. 2010;6(1):10-4.

14. Hishikawa K, Miura S, Marumo T, Yoshioka H, Mori Y, Takato T, Fujita T. Gene expression profile of human mesenchymal stem cells during osteogenesis in three-dimensional thermoreversible gelation polymer. Biochem Biophys Res Commun. 2004;317(4):1103-7.

15. Katoh S, Fujimaru A, Senthilkumar R, Preethy S, Abraham SJ Articular chondrocytes from osteoarthritic knee joints of elderly, in vitro expanded in thermo-reversible gelation polymer (TGP), exhibiting higher UEA-1 expression in lectin microarray. Regen Ther. 2020;14:234-237.

16. Rajalakshmy AR, Malathi J, Madhavan HN, Samuel JK Mebiolgel, a thermoreversible polymer as a scaffold for threedimensional culture of Huh7 cell line with improved hepatocyte differentiation marker expression and $\mathrm{HCV}$ replication. Indian $\mathrm{J}$ Med Microbiol. 2015;33(4):554-9.

17. Capeling MM, Czerwinski M, Huang S, Tsai YH, Wu A, Nagy MS, Juliar B, Sundaram N, Song Y, Han WM, Takayama S, Alsberg E, Garcia AJ, Helmrath M, Putnam AJ, Spence JR. Nonadhesive Alginate Hydrogels Support Growth of Pluripotent Stem Cell-Derived Intestinal Organoids. Stem Cell Reports. 2019;12(2):381-394.

18. Elçin YM, Dixit V, Gitnick G. Hepatocyte attachment on biodegradable modified chitosan membranes: in vitro evaluation for the development of liver organoids. Artif Organs. 1998;22(10):837-46. 